\title{
AÇÃO VOLUNTÁRIA COMO INSTRUMENTO DE APRENDIZADO E HUMANIZAÇÃO NA FORMAÇÃO MÉDICA
}

\section{VOLUNTARY ACTION AS A LEARNING AND HUMANIZATION INSTRUMENT FOR MEDICAL STUDENTS}

\author{
Paula Rissi Nogari ${ }^{*}$, Cassio Franco² \\ ${ }^{1}$ Acadêmica de Medicina do Centro Universitário Fundação Assis Gurgacz. ${ }^{2}$ Docente do \\ Centro Universitário Fundação Assis Gurgacz, Médico, Mestre em Metodologias Ativas \\ *Autor correspondente: paula.rissinogari@gmail.com, https://orcid.org/0000-0001-8542-7967
}

DOI: $10.35984 / f j h . v 2 i 1.156$

\section{RESUMO}

Propõe-se utilizar a ação social voluntária, no âmbito acadêmico, como ferramenta complementar ao processo de formação do médico. O objetivo foi refletir, a partir dos dados obtidos, sobre a praticabilidade da ação voluntária como ferramenta capaz de contribuir no processo pedagógico de construção de profissionais mais empáticos e sensíveis ao ser humano. Trata-se de um estudo exploratório, de caráter indutivo, com coleta de dados, através de questionário semiestruturado, aplicado aos discentes e docentes do curso de medicina de uma instituição de ensino superior, que participaram de uma ação voluntária em Setembro de 2018. Participaram da atividade 28 voluntários, destes, 21 responderam aos documentos. Os dados foram tabulados e armazenados em planilha do Microsoft Excel onde foram tratados estatisticamente para as questões de escala Likert, e para as questões abertas, realizou-se uma análise qualitativa das respostas. Os dados obtidos revelaram que o voluntariado trabalha valores morais e sociais e, se realizado no âmbito acadêmico, pode agregar qualidades ao aluno que irão fazer diferença na sua relação com o paciente. A prática pedagógica no contexto da ação voluntária promove a integração dos conhecimentos e trabalha muitas das habilidades e competências exigidas do médico e propostas nas Diretrizes Nacionais Curriculares.

Palavras-chave: empatia. graduação. voluntariado. medicina. humanização.

\begin{abstract}
It is proposed to use voluntary social action, in the academic field, as a complementary tool to the process of medical education. The objective was to reflect, from the data obtained, on the feasibility of voluntary action as a tool capable of contributing to the pedagogical process of building more empathetic and human-sensitive professionals. This was an exploratory, inductive study with data collection through a semi-structured questionnaire applied to medical students and teachers of a higher education institution who participated in a voluntary action in September 2018. 28 volunteers participated in the activity, of which 21 responded to the documents. Data were tabulated and stored in a Microsoft Excel spreadsheet where they were statistically treated for Likert scale questions, and for open questions, a qualitative analysis of the answers was performed. The data obtained revealed that volunteering works on moral and social values and, if done in the academic field, can add qualities to the student that will make a difference in their relationship with the patient. Pedagogical practice in the context of voluntary action promotes the integration of knowledge and works many of the skills and competencies required of the physician and proposed in the National Curriculum Guidelines. Keywords: empathy. graduation. volunteering. medicine. humanization.
\end{abstract}




\section{INTRODUÇÃO}

Em 1970, Michael Balint descreveu o termo "medicina centrada no paciente" como um conceito que incorporava ao saber médico questões relacionadas ao paciente, sua família e contexto sócio-econômico-cultural (FERREIRA et al; 2018).Na atualidade, busca-se na prática uma relação médico-paciente baseada fundamentalmente neste conceito, em oposição a uma medicina centralizada na doença. Isso exige, da formação médica, o desenvolvimento de habilidades que vão além da expertise e competência nas atitudes profissionais. Dentre estas habilidades, o médico do futuro precisa ver e sentir seu paciente, entender seu contexto e demonstrar empatia, sobretudo em tempos de avanços tecnológicos que estão mudando as formas de pensar a medicina. Segundo D'Avila (2010, p. 312) "o tratamento do paciente não pode prescindir de afeto por parte do médico, que no uso de seus conhecimentos técnicos não deve ignorar o outro ser humano, demonstrando empatia e compreensão".

As Diretrizes Curriculares Nacionais do Curso de Graduação em Medicina estabelecem que o egresso deve ter um perfil humanista, crítico e reflexivo, com senso de responsabilidade social e compromisso com a cidadania, como promotor da saúde integral do ser humano (BRASIL, 2014). Elencam competências e habilidades que se espera dos futuros profissionais médicos, tais como: ética, empatia, resolutividade, qualidade, responsabilidade, capacidade de avaliação e tomada de decisão, raciocínio crítico, comunicação, liderança, gerenciamento, trabalho em equipe multiprofissional. $E$, dentre os conteúdos essenciais da graduação do médico destaca a compreensão dos determinantes sociais, culturais, comportamentais, psicológicos, ecológicos, éticos e legais, nos níveis individual e coletivo, do processo saúde-doença (BRASIL, 2014).

As Diretrizes ainda prescrevem que a estrutura do curso de graduação em medicina deverá: utilizar metodologias que privilegiem a participação ativa do aluno na construção do conhecimento e a integração entre os conteúdos, além de estimular a interação entre o ensino, a pesquisa e a extensão/assistência; incluir dimensões éticas e humanísticas, desenvolvendo no aluno atitudes e valores orientados para a cidadania; promover a integração e a interdisciplinaridade em coerência com o eixo de desenvolvimento curricular, buscando integrar as dimensões biológicas, psicológicas, sociais e ambientais; utilizar diferentes cenários de ensino-aprendizagem permitindo ao aluno conhecer e vivenciar situações variadas de vida, da organização da prática e do trabalho em equipe multiprofissional (BRASIL, 2014).

Diante deste cenário, a motivação deste artigo surgiu da proposta de se utilizar a ação social voluntária, enquanto projeto de extensão, como uma ferramenta complementar ao processo de ensino, no cumprimento das Diretrizes pelas Instituições de Ensino Superior (IES). O objetivo é fazer uma reflexão sobre o aprendizado e os benefícios que esta experiência pode trazer para o médico em formação.

Para isso, avaliou-se a experiência de discentes e docentes de um curso de medicina de uma IES, através de questionários aplicados, após sua participação em uma ação voluntária que ocorreu em uma Aldeia de Índios Guaranis no Oeste do Paraná, em Setembro de 2018. A experiência dos voluntários forneceu informações 
valiosas para uma reflexão sobre a praticabilidade deste tipo de ação, como ferramenta capaz de contribuir no processo pedagógico de construção de profissionais mais empáticos e sensíveis ao ser humano e também mais conscientes dos contextos sociais. Necessário, então, entender qual é o significado dessa ação no universo acadêmico, principalmente na perspectiva docente e discente.

\section{METODOLOGIA}

Trata-se de um estudo exploratório, de caráter indutivo, com coleta de dados, através de questionário semiestruturado, aplicado aos discentes e docentes do curso de Medicina do Centro Universitário da Fundação Assis Gurgacz (FAG), que foram voluntários do Projeto Saúde Voluntária FAG na Aldeia Ocoy, em são Miguel do Iguaçu, em Setembro de 2018.

A pesquisa baseou-se em um Projeto de Extensão desenvolvido pelo curso de Medicina da FAG que teve como objetivo levar atendimento médico, palestras sobre prevenção em saúde e doação de medicamentos a uma comunidade indígena, composta por 160 famílias em situação de vulnerabilidade, no município de São Miguel do Iguaçu, na região Oeste do Paraná. Foram realizados 120 atendimentos médicos especializados (oftalmologia, clinica médica, ginecologia e obstetrícia e dermatologia), durante 06 horas de atendimento. A ação contou com o apoio da Equipe de enfermagem da Unidade de Saúde local e de funcionários da escola que atuaram como intérpretes auxiliando nas consultas dos pacientes que não falavam português. A equipe de voluntários foi responsável por montar toda a estrutura e se dividiu em consultórios adaptados em salas de aula da escola da aldeia, nos quais os discentes puderam participar dos atendimentos e da execução de toda a atividade juntamente com os docentes. Participaram da atividade 28 voluntários e aplicou-se 0 questionário a todos eles, mas apenas 21 responderam aos documentos. Destes, 06 são médicos docentes e os demais voluntários são discentes do curso de Medicina da FAG. O questionário constou com 18 questões: 10 fechadas em escala likert e 8 abertas e, por uma adequação ao tema proposto foram consideradas para este artigo 11 questões.

Os voluntários preencheram o questionário, dando sua opinião sobre a contribuição que a atividade voluntária trouxe para a formação acadêmica e no preparo psicológico e diferenciação do futuro profissional. Questionou-se, se ações voluntárias como a praticada, são capazes de aproximar docentes e discentes no processo de aprendizagem e se as IES devem incentivar este tipo de ação enquanto atividade extracurricular. Também interessou questionar aos voluntários qual o sentimento após a realização da atividade e como foi sua experiência. Por fim responderam se a atividade atingiu seu objetivo fizeram críticas e sugestões. Os questionários foram aplicados 06 meses após a realização da atividade voluntária e juntamente com os questionários foram coletados TCLE. Os dados coletados foram representados na forma de gráficos e tabelas e foram tabulados e armazenados em planilha do Microsoft Excel onde foram tratados estatisticamente para as questões de escala Likert, e para as questões abertas, foi realizada uma análise qualitativa das respostas. O projeto foi aprovado pelo Comitê de Ética em Pesquisa com Seres Humanos do Centro Universitário da Fundação Assis Gurgacz - FAG, sob oo 08930918.6.0000.5219. 


\section{RESULTADOS E DISCUSSÃO}

A ação voluntária é tradicionalmente entendida como atividade não remunerada em benefícios de outros, apresentando-se de diversas formas, desde uma assistência a indivíduos em situação de necessidade até esforços coletivos e organizados para melhorar a qualidade de vida de toda uma comunidade (DUGUID; MÜNDEL; SCHUGURENSKY, 2013). Em seu sentido amplo, a humanização está relacionada com a solidariedade, com a preocupação com o indivíduo em situação vulnerável e com o respeito à dignidade da pessoa humana (WALDOW; BORGES, 2011).

O altruísmo é tido como sinônimo de filantropia e solidariedade, sentimentos que fundamentam comportamentos e ações voluntárias de um indivíduo ou coletivo, em benefício do outro. Augusto Comte cunhou a palavra "altruísmo" em 1831 caracterizando-o como um conjunto de disposições humanas que levam os seres humanos a dedicarem-se aos outros (BRASIL, [s.d.]).

Segundo Esquerda (2016, p. 13), empatia pode ser definida como a "capacidade de uma pessoa transmitir a compreensão às emoções de outros indivíduos, o que implica uma capacidade de compreender como o outro se sente e de deixá-lo saber que esse entendimento existe". A empatia é um componente importante do profissionalismo médico, é básica para estabelecer uma relação médico- paciente adequada e está relacionada a uma melhor competência clínica e ética e menor estresse profissional. É um requisito para o cuidado centrado no paciente (ESQUERDA; YUGUERO, 2016).

A humanização e a empatia são o fluído vital da relação médico paciente, imprescindível para a boa prática médica. Essas virtudes estão intimamente ligadas ao tratamento pelo profissional de saúde do seu paciente como um todo e não apenas como uma pessoa portadora de doença, mas sim inserido num contexto sócioeconômico cultural. Conhecer a vulnerabilidade social, a diversidade e aprender sobre o altruísmo e a respeitar a dignidade da pessoa humana são fundamentais para um processo de descoberta da empatia e de humanização.

Discute-se se é possível ou não ensinar a empatia (BENEDETTO et al., 2014). Alguns estudos (NEUMANN et al., 2011) mostram que pode haver uma diminuição desta competência durante a formação de estudantes, porém, outros revelam que a empatia pode ser trabalhada. Um estudo Espanhol em que foram aplicados questionários a 191 estudantes da Faculdade de Medicina de Lleida apontou que o desenvolvimento da empatia em estudantes pode ser influenciado por circunstâncias externas, como por exemplo, as experiências educacionais, e que maiores níveis de empatia estão relacionados com o feito de haver participado de voluntariado social ou ter vivido próximo à doença de um amigo (ESQUERDA; YUGUERO, 2016).

Neste sentido, experiências educacionais devem promover atividades que desenvolvam a empatia e a humanização do acadêmico preparando-o para o futuro profissional, sobretudo, na área da saúde. Diversificar tais experiências pode enriquecer sobremaneira, não só o currículo dos acadêmicos, como também suas personalidades. Os dados coletados revelaram vários aspectos interessantes acerca desses valores buscados.

A pergunta representada na figura 1 questionou como foi a experiência dos voluntários. A maioria das respostas dividiu-se entre "gratificante" e "ótima" o que 
demonstra que mesmo sendo uma atividade gratuita, por muitas vezes exaustiva, de dedicação total ao outro, o sentimento é de bem estar e gratidão.

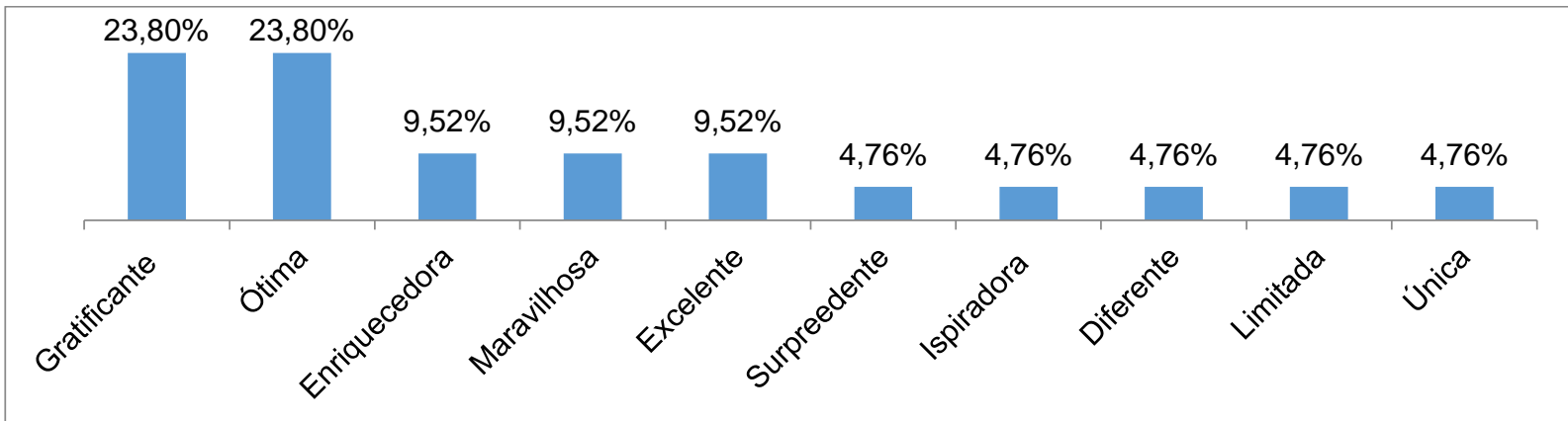

Figura 1. Demonstração em percentual das respostas para "como foi sua experiência?"

Na figura 2, em que se perguntou qual o principal sentimento no retorno para casa, verifica-se que a grande maioria dos voluntários referiu "gratidão", seguida por "satisfação". 9,52 \% mencionaram "dever" enquanto "compaixão", "aprendizado" e "humanizador" tiveram 4,76\% de ocorrência.

Gratidão e satisfação estão relacionadas com níveis de felicidade e, de fato, a literatura descreve que os atos de generosidade levam a um aumento de felicidade, funcionando como um gatilho para que o cérebro produza endorfinas, por um aumento do nível de serotonina e dopamina. Com atos de bondade há também liberação de ocitocina, contribuindo para a diminuição dos níveis tensionais e melhora da função imunológica (SAPIRO; MATIELLO, 2016).

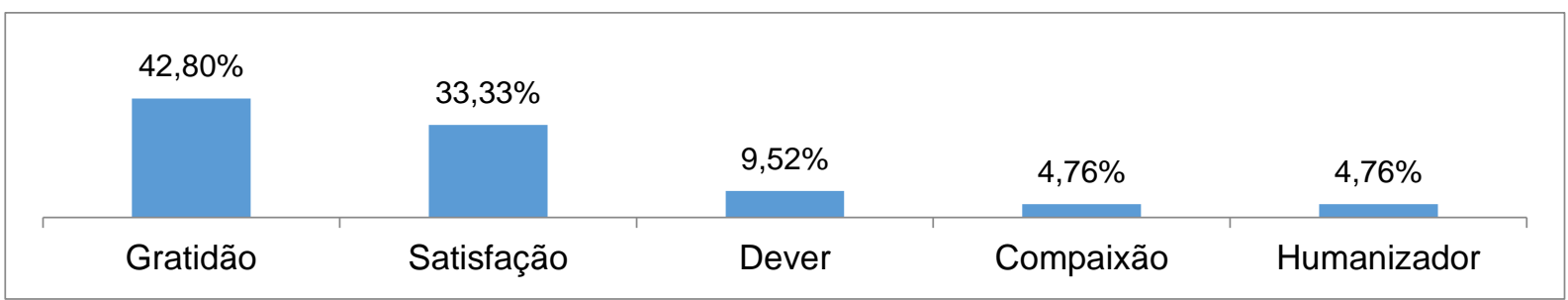

Figura 2 - Qual o sentimento no retorno para casa? Fonte: Próprio autor.

O voluntariado, portanto, é uma atividade que faz bem tanto para quem faz como para quem recebe, afinal pessoas mais felizes são mais empáticas. Resgata valores como responsabilidade social, o que justifica o sentimento de aprendizado e de dever. Também aproxima pessoas em uma causa benéfica e gratuita, gerando sentimentos de compaixão em relação ao outro e de transformação em relação a si mesmo, por que não dizer, humanizadora (MEDEIROS et al., 2014).

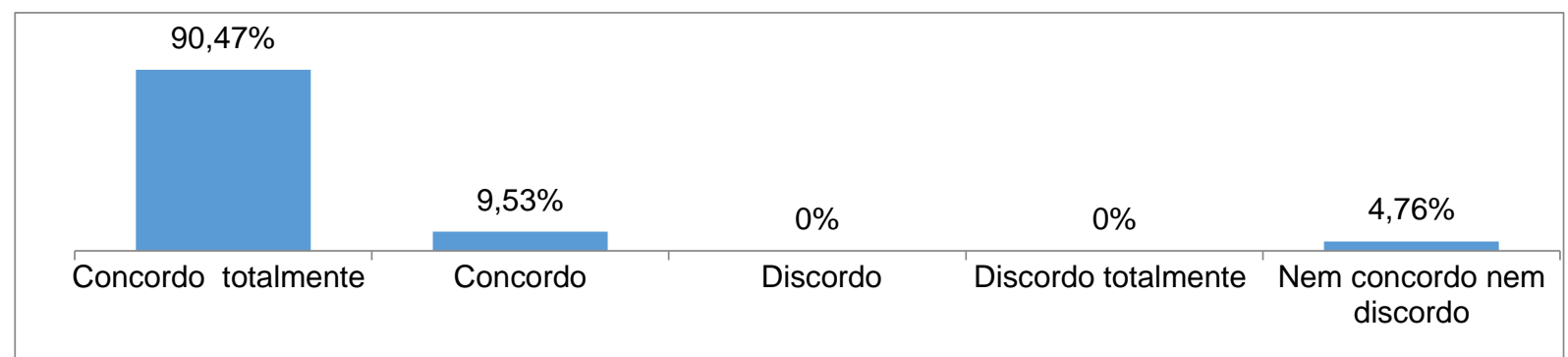

Figura 3 - A ação voluntária contribuiu de forma significante na minha formação médica, proporcionando um "olhar" mais humanizado, principalmente na visão holística da medicina centrada na pessoa e não na doença. Fonte: Próprio autor. 
Benedetto (2014, p. 520) assevera que "o conhecimento que se adquire com as emoções forjará mediante a reflexão vivências e, através delas, um conhecimento assimilado, duradouro, que transforma. Eis um paradigma moderno que a educação médica deve contemplar". Nota-se que $90,47 \%$ dos voluntários responderam que concordam totalmente que a ação voluntária contribuiu de forma significante na sua formação médica, proporcionando um 'olhar' mais humanizado, principalmente na visão holística da medicina centrada na pessoa e não na doença (figura 3).

Verifica-se que $76,19 \%$ concordaram totalmente que a ação voluntária contribuiu para que se sintam mais preparados para atender e acolher pessoas de culturas/etnias diferentes, proporcionando uma visão diferenciada dos demais profissionais (figura 4).

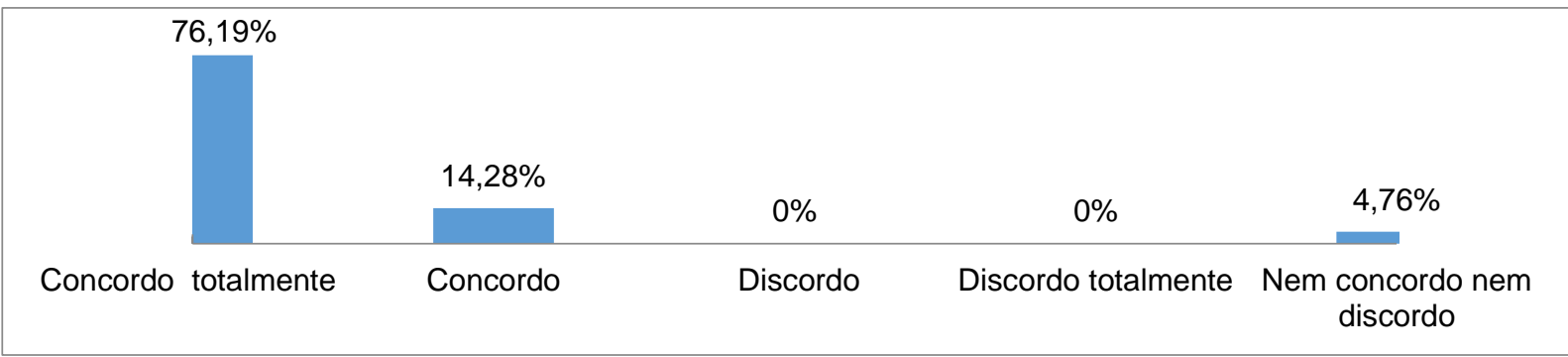

Figura 4 - A ação voluntária contribuiu para que você se sinta mais preparado para atender e acolher pessoas de culturas/etnias diferentes, proporcionando uma visão diferenciada dos demais profissionais? Fonte: Próprio autor.

Estas respostam harmonizam com os efeitos da atividade voluntária descritos em um estudo de caso sobre o programa de voluntariado da Cruz Vermelha no Canadá em que se constatou que o voluntariado ajuda a formar indivíduos que conduzem suas vidas com respeito, compaixão e humildade pelos outros e ajuda a incentivar a preocupação e consideração por todos os seres humanos. Essa experiência promove conscientização da pobreza e da marginalidade na comunidade, proporcionando ao voluntário aprendizado sobre questões dos idosos e populações vulneráveis e adquirir habilidades sociais e interpessoais (DUGUID; MÜNDEL; SCHUGURENSKY, 2013).

Os pesquisados foram questionados se participariam de outras ações voluntárias e por quê. A maioria respondeu que sim e as justificativas mais relevantes apresentaram um padrão representado no quadro 1, destacando-se "respeito ao futuro" e "experiência humanizadora".

Quadro 1 - Por que você participaria de novo de uma ação como a praticada?

- Experiência única

- Experiência gratificante

- Experiência humanizadora

- Respeito ao futuro

- Me ensinou a ser melhor
- Enriquecimento como ser humano

- Contato com uma cultura e

população diferente

- Ajudar a pessoas em necessidade

- Enriquecimento pessoal e profissional

Fonte: Próprio autor.

Um voluntário respondeu que participaria de novas ações voluntárias porque "ações sociais e voluntárias permitem atender um público diferente e o enriquecem como ser humano", enquanto outro respondeu que participaria novamente para FAG Journal of Health - ISSN 2674-550X, 2020, v.2, n.1, p. 25 
"ajudar uma comunidade necessitada e para aprender a ser mais humano e melhor". Outro respondeu "porque me ajudou a evoluir como profissional e como ser humano, além de me mostrar como realmente é a situação de vida desses povos".

A pesquisa questionou aos voluntários se concordavam com a assertiva de que as IES devem ser incentivadas a realizar atividades voluntárias, pois talvez o principal benefício seria despertar nos futuros profissionais de diversas áreas, a aproximação entre seres humanos de culturas e classes sociais diferentes, promovendo a humanização tão desgastada nos dias de hoje. 95,24\% dos voluntários concordaram totalmente (figura 5).

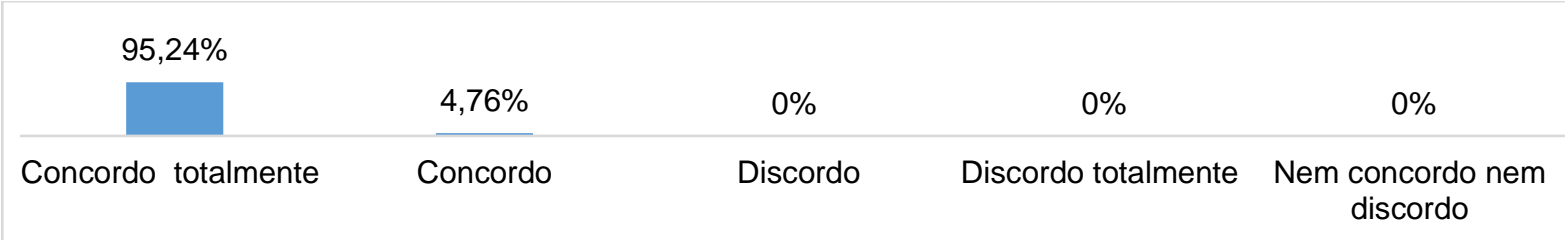

Figura 5 - As IES (Instituições de Ensino Superior) deveriam ser incentivadas à realizar atividades voluntárias, pois talvez o principal benefício seria despertar nos futuros profissionais de diversas áreas, a aproximação entre seres humanos de culturas e classes sociais diferentes, promovendo a humanização tão desgastadas nos dias de hoje. Fonte: Próprio autor.

Estes dados confirmam que além de experiência humanizadora o voluntariado fortalece alicerces morais já estabelecidos e ajuda a construir na prática outros novos. Trata-se também de uma experiência que proporciona aos envolvidos a descoberta de outra realidade, de outra cultura, da solidariedade e da responsabilidade social.

Quadro 2 - Por que você acredita que a ação voluntária cumpriu com o seu objetivo?

\begin{tabular}{|ll|}
\hline - Cromoção da saúde local & - Acesso a saúde facilitado \\
- Ajudar quem aguardava & - União dos voluntários em prol de \\
- Ajudar a quem precisa & - - Contribuir com uma vida \\
- Contato com realidade diferente & - Solução com ações simples \\
- Acolhimento do paciente &
\end{tabular}

Fonte: Próprio autor.

Outro ponto analisado no estudo foi sobre o objetivo da ação voluntária. Os voluntários foram questionados se o objetivo - levar atendimento médico especializado à população desassistida e vulnerável e ensinar sobre cuidados básicos à saúde - foi alcançado.

As questões eram abertas e, na maioria absoluta, as respostas foram sim. Porém ao justificarem os voluntários apresentaram outros objetivos alcançados pela ação, destacando-se: "acolhimento do paciente", "contribuir com uma vida", e a "união dos voluntários em prol de um ser humano", como se percebe no quadro $2 . \quad$ Este último objetivo evidencia o reconhecimento pelos voluntários do trabalho em equipe.

Apesar do objetivo proposto pelos organizadores ter sido pontuado por muitos voluntários, verifica-se a presença de outros objetivos de valores humanistas que foram atingidos individualmente. Um voluntário respondeu que a atividade contribuiu para seu "crescimento acadêmico" enquanto outro relatou que serviu de "aperfeiçoamento de princípios e valores médicos" (quadro 2). 
Percebe-se, portanto que a atividade voluntária teve o efeito de afetar suas vidas. Isso se dá por que o voluntariado provoca mudanças de comportamento no âmbito pessoal e social, uma vez que a atividade dá sentido "ao que se faz, ao que se tem e no modo como se vive". O exercício do voluntariado ressignifica o modo de pensar, sentir e de se relacionar entre indivíduo e sociedade. O aluno exerce um compromisso de cidadão orientado por valores como responsabilidade solidária, ética e generosidade (MARQUES, 2006).

A promoção desses valores acaba por influenciar no crescimento individual e profissional do voluntário. $O$ voluntariado contribui para o melhor entendimento de algumas disciplinas como aquelas ligadas à relação médico-paciente, e colabora no processo de formação profissional e para a vida, promovendo um resgate de valores de relacionamento de forma crítica e criativa, possibilitando ao aluno assumir a vida adulta com maturidade e capacidades diante da formação profissional (MARQUES, 2006).

Pode-se acrescentar que a ação voluntária como experiência acadêmica pode proporcionar uma aproximação entre os professores-médicos e os acadêmicos, fortalecendo essa relação com troca de conhecimentos adquiridos. $E$, a boa relação professor-aluno é um componente essencial na formação da identidade de futuros médicos e na construção da relação aluno/médico-paciente (RAMOS-CERQUEIRA; LIMA, 2009).

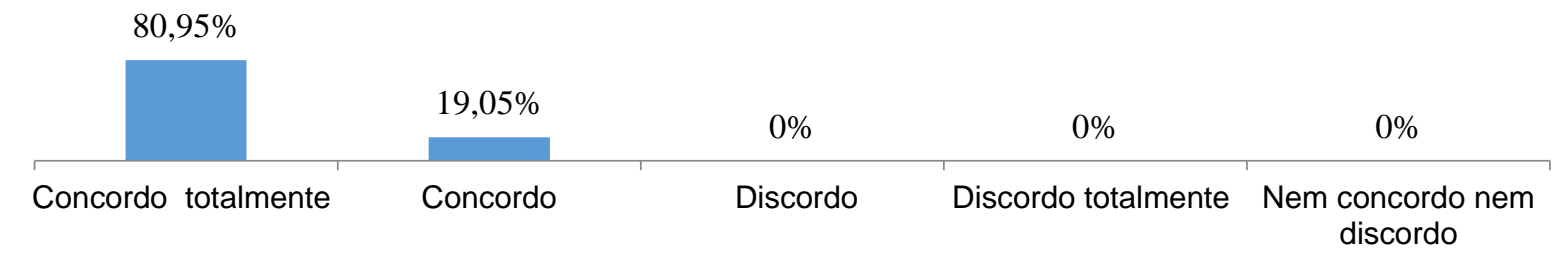

Figura 6 - As ações voluntárias em saúde, como a realizada, contribuem de forma pedagógica na formação profissional do médico e conseguem realizar a aproximação de conhecimentos no processo de ensino/aprendizagem entre docentes e discentes. Fonte: Próprio autor.

Neste sentido, 80,95\% dos pesquisados, concordaram totalmente com a afirmativa de que as ações voluntárias em saúde, como a realizada, contribuem de forma pedagógica na formação profissional do médico e conseguem realizar a aproximação de conhecimentos no processo de ensino/aprendizagem entre docentes e discentes (figura 6).

$\mathrm{Na}$ atividade em exame, coube ao docente transmitir conhecimento, sem perder a eficiência da semiologia - como um desafio no processo de ensino aprendizagem num cenário diverso da sala de aula, em que os desafios eram inúmeros tais como a língua, a estrutura precária, ausência de exames diagnósticos. O docente serviu como exemplo ao mesmo tempo em que dividiu sua experiência e expertise com os discentes. Para o docente, tratou-se de um atendimento fora do "padrão", um desafio, que exigiu sua experiência profissional para ensinar ao aluno como oferecer um atendimento clínico de qualidade mesmo com poucos recursos e muitos obstáculos.

Ciente da importância do voluntariado na esfera do aprendizado na graduação, a Faculdade de Medicina da Universidade do Porto (Portugal) incluiu no seu currículo a disciplina de "Formação Social e Humana", na qual os jovens acadêmicos são incentivados a completarem 50 horas de voluntariado relacionado com a área da Saúde. Segundo 0 docente responsável pela disciplina: "Conhecer os FAG Journal of Health - ISSN 2674-550X, 2020, v.2, n.1, p. 27 
constrangimentos próprios de quem vive num meio desfavorecido, as suas lutas e as suas dificuldades, contribui para uma melhor compreensão do doente e, em última análise, para que sejam melhores médicos" (MAGALHÃES, 2014).

Estas ações contribuem para a lapidação do futuro profissional de saúde, no que toca a sua formação humanística compreendida por uma maior empatia com o paciente. Uma experiência brasileira nesse sentido é a criação do Programa de Voluntariado da Escola de Medicina da Pontifícia Universidade Católica do Rio Grande do Sul, em que os acadêmicos são convidados a participar de atividades voluntárias de âmbito social, sendo-Ihes proporcionado o contato direto com comunidades e pessoas em condições de vulnerabilidade social, contribuindo para seu maior envolvimento humano, refletido em benefícios mútuos (SAPIRO; MATTIELLO, 2016).

Desenvolver ações sociais no ambiente acadêmico possibilita à instituição de ensino preparar o estudante para outras realidades, levando-o a conhecer populações vulneráveis e distantes dos grandes centros, praticando a educação fora da sala de aula, em uma interação entre professores e acadêmicos na mudança da realidade social.

Muitos países já vislumbraram o voluntariado, em diferentes contextos de saúde, como uma experiência essencial para se tornar um forte candidato a uma escola de medicina competitiva, por entenderem que esse conhecimento ajuda os aspirantes a médicos a se conectarem melhor com pacientes de diferentes origens étnicas e culturais, tornando-os mais eficazes para aliviar o seu sofrimento (WINDSOR UNIVERSITY SCHOOL OF MEDICINE, 2018).

Quadro 3 - Por favor, faça sua crítica e dê sua sugestão para uma próxima oportunidade.

- Existência de mais tradutores

- O projeto rendeu diversas consultas e palestras, levando conhecimento em saúde para a população.

- Realizar mais visitas na comunidade com ações multidisciplinares

Fonte: Próprio autor.

Por fim o questionário deixou um espaço para que os voluntários pudessem fazer críticas à atividade realizada e sugestões para uma próxima oportunidade. No quadro 3 estão representas as sugestões que mais se repetiram nas respostas dos voluntários. Alguns não responderam e dentre as respostas abertas destacou-se a de um docente que demonstrou interesse em "abranger e dar continuidade ao projeto para que os acadêmicos possam avaliar a eficácia de sua intervenção" e a resposta de um discente que sugeriu "incentivar desde o início do curso este tipo de atividade".

Estas respostas revelam que há interesse tanto de professores quanto de alunos para que estas atividades ocorram durante o curso, inclusive em mais de uma oportunidade para que os voluntários possam verificar, a posteriori, os resultados de suas ações. Esta avaliação pode ser de importante valor pedagógico.

Um dos voluntários respondeu que "o projeto foi incrível e o fez perceber a importância de uma anamnese e exame físico bem feitos além de entender o quanto a comunicação faz a diferença. Este foi o início de um grande projeto, que, com toda a certeza, deve ser levado a diante pelos acadêmicos. Poderia ser montada uma equipe multiprofissional com acadêmicos de nutrição, fisioterapia, enfermagem para proporcionar um atendimento mais completo e integral à comunidade" (quadro 3).

Esses dados demonstram que os voluntários perceberam o significado destas ações quando integradas ao curso, de forma extracurricular, e que também anseiam poder realizar mais ações desta natureza. 
Abordagens como estas, portanto, são exemplos de instrumentalização do voluntariado como ferramenta auxiliar na formação profissional e humanística do acadêmico, indo de encontro ao proposto pelas Diretrizes Curriculares Nacionais de 2001. As Diretrizes inseriram na matriz curricular da graduação em medicina no Brasil o objetivo de formar um profissional com várias características - dentre elas a formação humanista, princípios éticos, senso de responsabilidade social e compromisso com a cidadania (COSTA et al., 2012).

Possibilitam à instituição de ensino preparar o estudante para realidades diversas, levando o atendimento para populações vulneráveis, através da realização de projetos sociais, enquanto pratica a educação fora da sala de aula, em uma interação entre professores e alunos na mudança da realidade social e na construção de médicos mais completos, mais empáticos e humanos.

\section{CONCLUSÃO}

$\mathrm{Na}$ atualidade, a finalidade da educação superior não é simples e envolve um conjunto intencional e subjetivo de formação profissional mais abrangente do que apenas as ações educativas constantes na matriz curricular. $E$ as evidências indicam que as escolas médicas devem buscar novas estratégias para promover a empatia nos acadêmicos. Não por acaso os programas de residência vem exigindo do acadêmico a comprovação de horas em atividades voluntárias, pois, além da satisfação pessoal, exploram a empatia e possibilitam desenvolver habilidades valiosas como liderança, trabalho em equipe e raciocínio clínico.

No entanto, apesar da sua importância, na rotina da escola médica, existe baixo interesse e pouca adesão a este tipo de atividade. $O$ voluntariado no Brasil ainda passeia na esfera da informalidade e do assistencialismo abrigando estigmas em relação a quem o realiza. Os resultados da pesquisa conduzem à conclusão de que a prática pedagógica no contexto da ação voluntária promove a integração dos conhecimentos e trabalha muitas das habilidades e competências exigidas do profissional médico e propostas nas Diretrizes Nacionais Curriculares.

De uma maneira geral, os dados obtidos na presente pesquisa revelaram o voluntariado consegue trabalhar valores morais e sociais e, se realizado no âmbito acadêmico, pode agregar qualidades ao aluno que irão fazer diferença na sua vida profissional e na sua relação com o paciente. A atividade voluntária tem o potencial de complementar o ensino universitário com situações vividas que a sala de aula ou o consultório médico não conseguem contemplar, proporcionando o exercício de diversas habilidades e competências. O serviço voluntário compreende a inserção do aluno no universo do outro, em que assume um papel modificador do contexto de exclusão e vulnerabilidade social. Mais estudos com instrumentos adequados para aferir a mudança na empatia na realização de atividades voluntárias extracurriculares, possibilitarão mensurar o ganho para o acadêmico. A expansão dessa investigação será fundamental para identificar melhores estratégias a serem aplicadas na formação médica. Os pesquisadores entendem que há limitações no estudo que podem ter influenciado na obtenção dos resultados, devido ao tempo decorrido entre a realização da atividade e a coleta dos dados, pois, os voluntários tiveram que confiar na memória das sensações vividas após um período de 06 (seis) meses, e também devido à dependência dos pesquisadores na subjetividade dos participantes ao responderem os questionários. 
Contudo, os resultados são suficientes para afirmar que a experiência de se doar é humanizante e recompensadora, seja no âmbito de ensino ou do desenvolvimento pessoal, e que os objetivos da ação no universo acadêmico foram alcançados, o que se percebe nas palavras que mais ocorreram nas respostas dos discentes e docentes. Tais palavras remetem na construção de profissionais mais empáticos e sensíveis ao "outro" conscientes do seu papel social, integrando conhecimentos, ensino e humanização.

\section{REFERÊNCIAS}

ALMEIDA, R. M. DE S. S. A. O futuro médico ou o médico do futuro? - reflexões sobre formação, ensino e profissão. Revista Thêma et Scientia, v. 1, n. 1, p. 27-29, 2011.

BENEDETTO, M. A. C. DE et al. Educando as emoções para uma atuação ética: construindo o profissionalismo médico. Revista Brasileira de Medicina, v. 3, n. 1, p. 15-24, 2014.

BRASIL; COREME/COPESE. EDITAL n. 1/2018 - PROCESSO SELETIVO PROGRAMA DE RESIDÊNCIA MÉDICA 2019 - Imprensa Nacional, 2018. Disponível em: <http://www.in.gov.br/materia/-/asset_publisher/Kujrw0TZC2Mb/content/id/43101638/do32018-10-01-edital-n-1-2018-coreme-copese-processo-seletivo-programa-de-residenciamedica-2019-43101412>. Acesso em: 22 set. 2018.

\section{BRASIL; MINISTÉRIO DA EDUCAÇÃO. Diretrizes Curriculares Nacionais do Curso de} Graduação em Medicina, 2014.

BRASIL; SECRETARIA DA EDUCAÇÃO DO PARANÁ. Altruísmo. Disponível em: <http://www.filosofia.seed.pr.gov.br/modules/galeria/detalhe.php?foto=327\&evento=2>. Acesso em: 17 nov. 2018.

COSTA, B. E. P. et al. Reflexões sobre a importância do currículo informal do estudante de medicina. Scientia Medica, v. 22, n. 3, p. 162-168, 2012.

D'AVILA, R. L. A ética médica e a bioética como requisitos do ser moral: ensinamentos habilidades humanitárias em medicina. Revista Bioética, v. 18, n. 2, p. 311-327, 2010.

DUGUID, F.; MÜNDEL, K.; SCHUGURENSKY, D. Volunteer work, informal learning and social action. Rotterdam, Boston, Taipei: Sense, 2013.

ESQUERDA, M.; YUGUERO, O. La empatía médica, ¿nace o se hace? Evolución de la empatía en estudiantes de medicina. Atención Primaria, v. 48, n. 1, p. 8-14, 2016. DOI: 10.1016/j.aprim.2014.12.012.

FERREIRA, A. et al. Método clínico centrado na pessoa e sua utilização nas habilidades de comunicação. Periódicos Univag, v. 2, p. 3-5, 2018.

MAGALHÃES, O. Voluntariado passa a ser "cadeira" na Faculdade de Medicina "Notícias UP. Disponível em: <https://noticias.up.pt/voluntariado-passa-a-ser-cadeira-nafaculdade-de-medicina/>. Acesso em: 8 out. 2018.

MARQUES, V. L. [UNIFESP]. Voluntariado: motivos e repercussões na vida pessoal, social e acadêmica dos alunos de graduação em medicina, voluntários em programas na área de saúde. 2006. 
MEDEIROS, N. S. et al. Avaliação do desenvolvimento de competências afetivas e empáticas do futuro médico. Revista Brasileira de Educação Médica, v. 37, n. 4, p. 515-525, 2014. https://dx.doi.org/10.1590/S0100-55022013000400007.

NEUMANN, M. et al. Empathy Decline and Its Reasons: A Systematic Review of Studies With Medical Students and Residents. Academic Medicine, v. 86, n. 8, p. 996-1009, ago. 2011. DOI: 10.1097/ACM.0b013e318221e615.

RAMOS-CERQUEIRA, A. T. DE A.; LIMA, M. C. P. A formação da identidade do médico: implicações para o ensino de graduação em Medicina. Interface - Comunicação, Saúde, Educação, v. 6, n. 11, p. 107-116, 2009. DOI: 10.1590/S1414-32832002000200008.

SAPIRO, A.; MATTIELLO, R. Voluntariado: benefício a quem presta e a quem recebe. Scientia medica, v. 26 , n. 4, p. 14, 2016. DOI: http://dx.doi.org/10.15448/19806108.2016.4.25631.

SEEGMÜLLER, E. F.; GIELOW, R. Formação Médica : uma proposta diante das demandas da sociedade. Experiência da Pontifícia Universidade Católica do Paraná-PUCPR. p. 9-22, 2008.

WALDOW, V. R.; BORGES, R. F. Cuidar e humanizar: relações e significados. ACTA Paulista de Enfermagem, v. 24, n. 3, p. 414-418, 2011. http://dx.doi.org/10.1590/S010321002011000300017.

WINDSOR UNIVERSITY SCHOOL OF MEDICINE. How Volunteer Work Helps You Secure Admission In A Medical School. Disponível em: <https://www.windsor.edu/b/admissionmedical-school-volunteer-work/>. Acesso em: 29 jul. 2018. 